\title{
Cultura da inovação pelas práticas da experiência do cliente
}

\author{
Culture of innovation through customer experience practices \\ Cultura de innovación a través de prácticas de experiencia del cliente
}

Recebido: 13/09/2021 | Revisado: 21/09/2021 | Aceito: 22/09/2021 | Publicado: 24/09/2021
Gisele Bianchini
ORCID: https://orcid.org/0000-0002-5957-926X Universidade Federal do Paraná, Brasil E-mail: giselebianchini2017@gmail.com
Osmildo Sobral dos Santos
ORCID: https://orcid.org/0000-0003-3797-5971 Faculdade de Tecnologia de Mauá, Brasil E-mail: osmildosobral@gmail
Marcos de Oliveira Morais
ORCID: https://orcid.org/0000-0002-5981-4725 Universidade Santo Amaro, Brasil Universidade Estácio de Sá, Brasil E-mail: marcostecnologia@ig.com.br
Jose Flavio Messias
ORCID: https://orcid.org/0000-0003-1871-7002 Centro Universitário ENIAC, Brasil E-mail: jflaviomessias@hotmail.com
Douglas Leonardo de Lima
ORCID: https://orcid.org/0000-0002-3868-1222 Universidade Nove de Julho, Brasil E-mail: douglas.lima20@uni9.edu.br
Evandro Ferigato
ORCID: https://orcid.org/0000-0003-2044-1324 Centro Universitário Campo Limpo Paulista, Brasil E-mail: evandroferigato@gmail.com

\begin{abstract}
Resumo
Pretende-se com esse estudo analisar e identificar como as práticas da Experiência do Cliente, juntamente com a Cultura da inovação, podem trazer resultados às empresas. As ações de monitoramento e aprimoramento da experiência do cliente levam a empresa a redesenhar as interações com o cliente por todos os pontos e momentos de contato. Mapear as jornadas de seus clientes e os pontos de contatos mais importantes, leva a implantação de uma cultura organizacional inovadora que regerá todas as ações de relações internas e externas da empresa. A metodologia de pesquisa utilizada foi uma pesquisa exploratória, baseada na aplicação de questionários construído com aparato teórico baseado nas boas práticas aplicadas em grandes empresas, sobre Cultura da Inovação, Customer Success e Experiência do Cliente, uma interface entre estes três campos mediante uma análise comparativa, via questionário, com 24 empresas participantes do Projeto Agente Local de Inovação (ALI) de diversos segmentos de micro e pequeno porte, localizadas na região norte da cidade São Paulo, selecionadas pelo Sebrae. Como resultado, espera-se poder contribuir para aprimoramento da gestão de empresas que participam do Projeto ALI e, principalmente, em seus comportamentos empreendedores.
\end{abstract}

Palavras-chave: Cultura organizacional; Cultura da inovação; Experiência do cliente; Gestão de pessoas.

\begin{abstract}
The aim of this study is to analyze and identify how the Customer Experience practices, together with the Culture of Innovation, can bring results to companies. The actions to monitor and improve the customer experience lead the company to redesign customer interactions at all points and moments of contact. Mapping your customers' journeys and the most important contact points leads to the implementation of an innovative organizational culture that will govern all the company's internal and external relations actions. The research methodology used was an exploratory research, based on the application of questionnaires built with theoretical apparatus based on good practices applied in large companies, on Culture of Innovation, Customer Success and Customer Experience, an interface between these three fields through a comparative analysis, via a questionnaire, with 24 companies participating in the Local Innovation Agent Project (ALI) from various micro and small segments, located in the northern region of the city of São Paulo, selected by Sebrae. As a result, it is expected to be able to contribute to the improvement of the management of companies that participate in the ALI Project and, mainly, in their entrepreneurial behavior.
\end{abstract}

Keywords: Organizational culture; Culture of innovation; Customer experience; People management. 


\section{Resumen}

El objetivo de este estudio es analizar e identificar cómo las prácticas de Experiencia de Cliente, junto con la Cultura de Innovación, pueden aportar resultados a las empresas. Las acciones para monitorear y mejorar la experiencia del cliente llevan a la empresa a rediseñar las interacciones con el cliente en todos los puntos y momentos de contacto. Mapear los viajes de sus clientes y los puntos de contacto más importantes conduce a la implementación de una cultura organizacional innovadora que regirá todas las acciones de relaciones internas y externas de la empresa. La metodología de investigación utilizada fue una investigación exploratoria, basada en la aplicación de cuestionarios construidos con aparatos teóricos basados en buenas prácticas aplicadas en grandes empresas, sobre Cultura de Innovación, Éxito del Cliente y Experiencia del Cliente, una interfaz entre estos tres campos a través de un análisis comparativo, a través de un cuestionario, con 24 empresas participantes en el Proyecto Agente Local de Innovación (ALI) de varios micro y pequeños segmentos, ubicados en la región norte de la ciudad de São Paulo, seleccionados por Sebrae. Como resultado, se espera poder contribuir a la mejora de la gestión de las empresas que participan en el Proyecto ALI y, principalmente, en su comportamiento emprendedor.

Palabras clave: Cultura de la organización; Cultura de innovación; Experiencia del cliente; Gestión de personas.

\section{Introdução}

O presente artigo aborda a gestão da experiência do cliente como elemento para geração de inovação dentro das empresas.

A experiência do cliente e a cultura da inovação são duas vertentes estudadas no Projeto ALI, Agente Local de Inovação, dentre as 13 atualmente mensuradas. Seu objetivo é mensurar o grau de maturidade para a empresa inovar.

O estudo etnográfico que o Projeto ALI propõe com a metodologia do Job to be done traz a mudança de postura das empresas em observar os comportamentos do consumidor, os questionamentos pessoais com bases nas quatro forças emocionais (incômodos, motivações, hábitos e ansiedades) que inspiram as empresas a obter ideias que os próprios consumidores nunca teriam sido capazes de verbalizar. E essa compreensão do comportamento corrente dos consumidores tem muito mais chances de serem bem-sucedidas.

Uma parcela significativa das empresas é mal avaliadas pelos consumidores por não ouvirem seus clientes. Empresários e seus colaboradores, não são inspirados para agir com eficácia, seja por não se sentirem engajados ou conectados, seja pela falta de empatia com os clientes.

Diversas pesquisas são encontradas a respeito de como as empresas inovam e da atual necessidade de lidarem com o tema de maneira mais prática; todavia segundo Trías de Bes e Kotler (2011), há um descontentamento em relação da forma como a inovação é realizada.

As empresas pesquisadas percebem que é impossível inovar se não prestarem atenção no consumidor final. E a inovação real criada, seja ela, produto, serviço, forma de comercialização, processos, estrutura de parceria, mais cedo ou mais tarde deve ser aceitapelo cliente final, que tomará a iniciativa de validar ou não a inovação proposta. Essa mudança de postura de consumo, envolve um esforço que o consumidor só fará se obtiver um benefício claro e superior dele.

Pretende-se com esse estudo analisar e identificar como as práticas da Experiência do Cliente juntamente com a Cultura da inovação podem trazer resultados às empresas.

A metodologia de pesquisa utilizada foi no desenvolvimento do presente trabalho de natureza qualitativa e exploratória, baseada na aplicação de questionários construído com aparato teórico baseado nas boas práticas aplicadas em grandes empresas, sobre Cultura da Inovação, Customer Success e Experiência do Cliente.

Como resultado, espera-se poder contribuir para o aprimoramento da gestão da inovação nas empresas que participam do Projeto ALI e, principalmente, em seus comportamentos empreendedores.

Este artigo compõe-se de cinco capítulos, sendo este o primeiro. Os demais são: Capítulo 2-Referencial teórico: revisão bibliográfica sobre os temas abordados neste artigo; Capítulo 3-Procedimentos metodológicos: com a discussão da metodologia utilizada para caracterizar, quanto a seu método, abordagem e técnicas, quais as formas mais indicadas para o 
presente artigo; Capítulo 4-Análise e discussão dos dados: são apresentadas a discussão e a interpretação de seus principais resultados; Capítulo 5-Considerações finais: é dedicado ao fechamento do artigo e as sugestões para trabalhos futuros.

\section{Referencial Teórico}

Nas seções seguintes, são apresentados os elementos conceituais necessários ou correlatos ao método proposto. Serão tratados os temas: Cultura organizacional, Missão, Cultura da inovação, Gestão de pessoas, A equipe de trabalho, e A experiência do cliente.

\subsection{Cultura organizacional}

Para Chiavenato (2005) cada empresa tem sua própria cultura que ela mantém e cultiva, é o conjunto de hábitos e crenças que foram estabelecidos por normas, valores atitudes e expectativas e que são compartilhadas por todos os funcionários da organização. Ainda a sobrevivência e o crescimento da empresa, ocorrem na medida que ela consegue se ajudar e se adaptar às mudanças em seu ambiente e da empresa.

De acordo com Mintzberg, Ahlstrand e Lampel (2010), a cultura organizacional é a base da organização e sua força está em legitimar as crenças e os valores compartilhados entre os seus membros e diferenciá-la das demais organizações

Morais, Costa Neto e Santos et.al. (2020) esclarece que a cultura de uma empresa tem forte ligação com a liderança de seu criador, seu líder, pois tem seu elo nos primórdios da fundação da organização. É algo compartilhado entre os membros de uma equipe, sendo a forma que melhor os resultados criando mecanismos para resolução de problemas, ou seja, a cultura organizacional nada mais é do que os valores, as crenças, os objetos, normas dentre outros fatores que compõe uma organização. (Ibidem, 2020)

Fonseca, Salles, Santos e Freitas (2021) indicam que a definição de cultura de uma organização passa pelo entendimento da sua personalidade e do seu caráter, compreendendo seus valores, crenças e pressupostos. Norteia o comportamento, as interações, a forma como as decisões devem ser tomadas e como as atividades de trabalho devem ser realizadas por seus colaboradores. Cada organização está ligada à sua cultura, compreendendo valores, normas, regulamentos, sistemas de crenças e códigos de conduta, para direcionar suas operações e orientar o comportamento dos seus membros. (Ibidem, 2021)

\subsection{Missão}

Chiavenato (2005) define que a missão de uma empresa é a razão de ser pela qual ela foi criada e desenvolvida, enquanto a visão reflete a ideia de futuro da empresa. Enquanto a missão é racional e leva todos à ação, a visão é passional e leva ^a motivação para atingir os objetivos e transformá-la em realidade. Quando todos dentro da empresa, dirigentes e colaboradores conhecem e comungam destes conceitos, eles não precisam adivinhar o que se espera deles, pois juntos, estes conceitos oferecem clareza, consenso e compromisso.

Sobre este assunto Terra (2012) opina que a cultura organizacional é representada,em parte, por sua missão e valores e deve ser ancorada e construída por ações vinda de seus dirigentes que valorizem fatos, notícias que exemplifiquem os valores perseguidos.

Dyer, Dyer Jr e Dyer (2007) comenta que a cultura organização é provavelmente o fator mais significativo no desenvolvimento de uma boa equipe de trabalho. A cultura da organização defini o que é certo ou errado, o que é valorizado, como alguém se envolve em problemas e como es espera que os colaboradores vivem o mundo corporativo de maneira sistêmica. Se acultura da empresa demonstra resistência à importância de trabalho em equipe, qualquer tentativa de incentivar 
a colaboração, a participação ou o envolvimento será vista como uma ação temporária ou uma manipulação por parte da gestão.

Kotler, Kartajaya e Setiawan (2012) conceitua que criar uma boa missão significa apresentar uma nova perspectiva de negócios que pode transformar a vida dos consumidores, o qual ele chama de "práticas inovadoras". Ele acredita que há sempre uma boa história por trás de uma boa missão. Portanto, difundir a missão junto aos consumidores envolve uma história que emociona as pessoas. Em outras palavras, a concretização da visão requer a participação do consumidor. Assim, o empoderamento do consumidor é fundamental, conforme indicado na Figura 1:

Figura 1 - As três características de uma boa missão.

Práticas Inovadoras $\begin{gathered}\text { Histórias que emocionam as } \\ \text { pessoas }\end{gathered} \quad \begin{gathered}\text { Empoderamento do } \\ \text { Consumidor }\end{gathered}$

Fonte: Adaptado de Kotler, Kartajaya e Setiawan (2012).

Terra (2012) comenta que a criatividade e inovação não são fenômenos quedependem puramente de esforço mental ou individual. $\mathrm{O}$ ambiente organizacional influencia na frequência e na expressão do comportamento inovador. É nos relacionamentosinterpessoais e nas suas dinâmicas dentro da organização que a inovação pode aparecer.

\subsection{Cultura da inovação}

Para Schumpeter (1982), a inovação é o processo resultante da introdução de um novo produto com o qual os consumidores ainda não estão acostumados, da aplicação um novo método de produção, da abertura de um novo mercado, da utilização de uma nova fonte de suprimento de matérias primas ou insumos e, por fim, da execução da nova organização de qualquer indústria. Assim, uma inovação é considerada bem-sucedida caso possa ser vendida para os consumidores em uma quantidade e a um preço que proporcione lucro.

Terra (2012) acrescenta que a cultura organizacional, no contexto da gestão da inovação poderá ser sempre lembrada como um facilitador ou bloqueador dos esforços para conseguir resultados empresariais por meio de esforços de inovação. E dentro do espaço organizacional a inovação pode surgir de duas maneiras: através da cultura organizacional e de ferramentas e processos que favoreçam o trabalho em equipe, o conhecimento e o fluxo de informações.

$\mathrm{Na}$ continuidade dos estudos, Terra (2012) pondera que o espaço social para a inovação surge de duas maneiras: através da cultura organizacional e de também através de ferramentas e processos internos que incentivem a colaboração, o trabalho em equipe e o conhecimento. As principais características de um ambiente organizacional voltado à inovação são:

a) Estímulo à criatividade;

b) Humor no ambiente de trabalho: no âmbito interno da empresa, a tolerância para os momentos de humor entre colaboradores (desde que não agressivos e exagerados) pode levar à criação de um ambiente no qual as pessoas têm possibilidade de derrotar o pensamento rotineiro pela originalidade. Espaços de trabalho: espaços físico abertos, humanísticos, não hierárquicos e ecológicos facilitam os contatosinformais, a produtividade, a capacidade de inovação dos trabalhadores e a comunicação em todos os sentidos;

c) Pressão do tempo: saber identificar quando a pressão do tempo na resolução de desafios deve ser alta ou baixa junto aos colaboradores; e, 
d) Papel da administração: a cultura da organização começa no topo; o comportamento dos gestores afeta sobre maneira os comportamentos das demais pessoas na organização. Saber escutar, encorajar suas equipes a expor ideias, testar seus conceitos e compartilhar conhecimento.

Já Morais, Brejão, Santos e Costa Neto (2019) identificam diversos fatores responsáveis para a abordagem do processo de inovação, no qual a estrutura e a estratégia organizacional são os principais eixos para a obtenção desta relação, tendo a empresa como foco principal. Por meio de um conjunto de fatores e ferramentas gerenciais, torna-se possível uma inter-relação e também uma interação entre todos os aspectos envolvidos; entre eles destacam-se as pessoas (capital humano), conhecimento, tecnologia, flexibilidade e gestão, entre outros, estabelecendo uma rede e possibilitando um crescimento organizacional voltado ao processo de inovação.

Na continuidade sobre o assunto Morais, Costa Neto e Santos et.al. (2020) assinala que busca pela inovação deve ser observada e compartilhada por todos os departamentos e colaboradores envolvidos na organização independentemente do nível hierárquico, possibilitando assim a criação de vantagem competitiva e geração novos desenvolvimentos.

\subsection{Gestão de pessoas}

Para Terra (2012) as pessoas podem inovar muito mais do que acreditam ser capazes de fazer. Não apenas colaboradores, mas também clientes e fornecedores podem fazertoda a diferença (Figura 2).

Figura 2 - Foco em pessoas como recursos humanos para inovação.

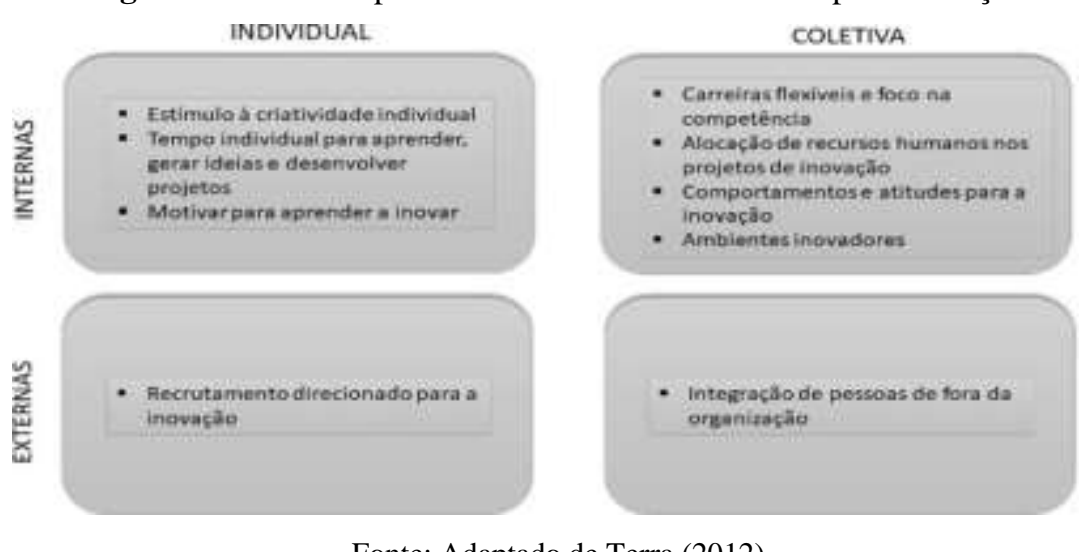

Fonte: Adaptado de Terra (2012).

A Figura 2 retrata as atividades fundamentais para a inovação, nas quais envolvemcriatividade e, portanto, não podem ser automatizadas. A inovação é resultado exclusivo da atividade humana, à medida que a automação avança sobre as funções executadas pelos sereshumanos, cresce uma distinção entre as funções que podem ser executadas por máquinas e as que só podem sê-lo pelos seres humanos.

A busca pela inovação deve ser observada e compartilhada por todos os departamentos e colaboradores envolvidos na organização independentemente do nível hierárquico, possibilitando assim a criação de vantagem competitiva e geração novos desenvolvimentos.

\subsection{A equipe de trabalho}

Chiavenato (2005) pondera que as equipes de trabalhos são relações afetivas e emocionais, conexões entre as pessoas. Elas misturam diversidade e unidade, abertura eaceitação, honestidade e empatia, criticismo e reconhecimento, 
confiança e assunção de risco, para criar algo maio. Quando a empresa oferece oportunidades de realização, a empresa pode ser o nicho adequado em que as competências individuais se desenvolvem e crescem em prol da organização.

Davis e Newstrom (1996) elucida que quando os colaboradores sabem seus objetivos, contribuem de maneira responsável e entusiasticamente para a tarefa esse são apoio mútuo, demonstrando trabalho em equipe. Na continuidade dos estudos acrescenta que existem pelo menos quatro ingredientes que contribuem para o desenvolvimento de umtrabalho em equipe: um ambiente de apoio, habilidades adequadas "as necessidades do cargo, metas superiores e recompensas à equipe (Ibidem, 1996).

Terra (2012), mostra que a familiaridade e a similaridade de pensamentos facilitam a cooperação, porém, a colaboração entre iguais é pouco eficiente para a inovação.A inovação exige um conflito e um confronto de perspectivas e ideias diferentes, e que é preciso que diferentes áreas da empresa com experiências e vivências diferentes interajam entre si. Para que áreas tão diferentes como marketing, pesquisa e desenvolvimento ou finanças e vendas possam trabalhar em conjunto para gerar inovação é necessário:

1) Definir um alvo e uma motivação que seja comum a todos;

2 ) Garantir que cada equipe de cada departamento não seja sufocada por hierarquias ou disputas internas de poder;

3) Liderança empática;

4) Comunicação clara e com livre acesso à informação;

5) Reconhecimento da liderança de atitudes prestativas;

6) Garantir tempo às equipes para reflexão e recursossuficientes de dedicação aos projetos de inovação;

7) Ter mecanismos de recompensa coletivas que meçam a tentativa e não punam a falha;

8) Ter espaços físicos abertos e layouts criativos e arejados são necessários para um ambiente de colaboração eficaz.

Ainda discorrendo sobre o tema Terra (2012) propõe que não é mais possível pensar seriamente em inovação nos dias de hoje sem falar de redes de relacionamento, colaboração e confiança. A vantagem competitiva está diretamente relacionada ao capital de relacionamento. E, toda empresa deve se dedicar continuamente na construção de uma reputação com aptidões de colaboração com parceiros, intermediários, clientes, fornecedores efuncionários para gerar valor.

No entanto, Terra (2012) ressalta que os relacionamentos para inovação não são comprados, são construídos a partir da combinação de recursos e competências internas e externas, ou seja, interligar as estratégias de inovação às necessidades dos clientes e oportunidades de mercado muito mais amplo que qualquer empresa sozinha poderia ter dentrode seu ambiente interno.

\subsection{A experiência do cliente}

Segundo Pine II e Gilmore (1999) estamos entrando em uma nova era de concorrência chamada economia da experiência. Os clientes querem experiências memoráveis e as empresas devem se tornar provedoras de experiências, pois seus produtos e serviços não passam de acessórios para envolver o cliente. E no final de tudo, o valor da experiência permanece na memória de qualquer pessoa envolvida no evento.

Zeithaml et al. (1990) apud Santos (2006) propõem alguns fatores que influenciam a formação das expectativas dos clientes em relação ao serviço a ser prestado tais como comunicação oral; necessidades e desejos pessoais; experiência anterior; comunicação externa; e preço. 
Kotler, Kartajaya e Setiawan (2012) define comportamento do consumidor como a "área que estuda como pessoas, grupos e organizações selecionam, compram, usam e descartam produtos, serviços, ideias ou experiências para satisfazer suas necessidades e seus desejos".

Já Michelli (2017) disserta que os clientes são guiados pelo que denomina como "encaminhamento" e há intensão de entrega do melhor produto/serviço baseado na experiência do cliente.

Para Disney Institute (2011) a satisfação do cliente é um alvo em constante movimento e não importa se você chama as pessoas de clientes, colaboradores ou pacientes, todos devemos satisfazer os convidados ou arriscamos perdê-los. O atendimento de qualidade significa superar as expectativas dos convidados e prestar atenção aos detalhes. Detalhes que talvez nunca cheguem a ser notados de forma consciente como as portas dos quartos do hotel, que possuem dois olhos mágicos: um na altura normal e outro na altura dos olhos de uma criança.

Na continuidade dos estudos da Disney Institute (2011), cada convidado que visita a Walt Disney World deve levar algo a mais, que supere suas expectativas; é preciso primeiro satisfazer e então exceder as expectativas dos seus clientes se quiser desenvolveruma reputação pelo atendimento de qualidade.

Kotler, Kartajaya e Setiawan (2012) fazem uma comparação entre Marketing na qual indica que, o mundo presencia o aparecimento do Marketing 3.0 onde os profissionais dessa área devem estar aptosa detectarem as ansiedades e os anseios humanos, profundamente enraizados na criatividade, cultura, tradição e meio ambiente. Buscam não apenas satisfação funcional e emocional, mas também satisfação espiritual, nos produtos e serviços que escolhem. Pode-se entender tais comparações ao observar o Quadro 1.

Quadro 1 - Comparação entre Marketing 1.0, 2.0 e 3.0.

\begin{tabular}{|c|c|c|c|}
\hline & $\begin{array}{l}\text { Marketing } 1.0 \text { centrado no } \\
\text { Produto }\end{array}$ & $\begin{array}{l}\text { Marketing } 2.0 \text { centrado } \\
\text { no Consumidor }\end{array}$ & $\begin{array}{l}\text { Marketing 3.0 Centrado } \\
\text { para os Valores }\end{array}$ \\
\hline Objetivo & Vender Produto & $\begin{array}{l}\text { Satisfazer e reter os } \\
\text { consumidores }\end{array}$ & $\begin{array}{l}\text { Fazer do mundo um } \\
\text { lugar melhor }\end{array}$ \\
\hline Forças Propulsoras & Revolução Industrial & $\begin{array}{l}\text { Tecnologia da } \\
\text { Informação }\end{array}$ & $\begin{array}{l}\text { Nova onda de } \\
\text { tecnologia }\end{array}$ \\
\hline $\begin{array}{c}\text { Como as empresas } \\
\text { veem o mercado }\end{array}$ & $\begin{array}{l}\text { Compradores de massa,com } \\
\text { necessidades físicas }\end{array}$ & $\begin{array}{l}\text { Consumidor inteligente, } \\
\text { dotado de coração e mente }\end{array}$ & $\begin{array}{l}\text { Ser humano pleno, com } \\
\text { coração, mente e espírito }\end{array}$ \\
\hline Conceito de Marketing & $\begin{array}{l}\text { Desenvolvimento de } \\
\text { produto }\end{array}$ & Diferenciação & Valores \\
\hline $\begin{array}{r}\text { Diretrizes de Marketing } \\
\text { da empresa }\end{array}$ & $\begin{array}{l}\text { Especificação do } \\
\text { produto }\end{array}$ & $\begin{array}{l}\text { Posicionamento do } \\
\text { produto e da empresa }\end{array}$ & $\begin{array}{l}\text { Missão, Visão e Valoresda } \\
\text { Empresa }\end{array}$ \\
\hline ao ae & Funcional & Funcional e Emocional & $\begin{array}{l}\text { Funcional, emocional e } \\
\text { espiritual }\end{array}$ \\
\hline $\begin{array}{r}\text { Interação com os } \\
\text { consumidores }\end{array}$ & $\begin{array}{l}\text { Transação do tipo um- } \\
\text { para-um }\end{array}$ & $\begin{array}{l}\text { Relacionamento um- } \\
\text { para-um }\end{array}$ & Colaboração um-para-um \\
\hline
\end{tabular}

Fonte: Adaptado de Kotler, Kartajaya e Setiawan (2012).

Michelli (2017) demonstra o processo de Mudança de Cultura "DRIVEN TO L.E.A.D". da Mercedes-Benz, em tradução Listen=Ouvir, Emphatize=Ter empatia, Value=Agregar Valor e Delight=Encatar lançado em setembro de 2011.

Discorrendo sobre este assunto, Michelli (2017) mostra que foram entrevistados $10 \%$ dos diretores das concessionárias Mercedes-Benz e foram enviaram questionários para 3000 funcionários para reunir suas ideias e percepções sobre a qualidade das experiências do cliente fornecidas pelos revendedores. $\mathrm{O}$ resultado da pesquisa junto aos funcionários foi a base para a grade de tópicos para o treinamento interno. $\mathrm{O}$ treinamento era baseado em 3 pilares: 
1) Conscientização: aquilo que o funcionário considera bom o suficiente pode nãoser uma experiência inesquecível para o cliente.

2) Perspectiva: a experiência que sua empresa está proporcionando ao cliente secompara à melhor das melhores?

3) Clientes encantados e emocionalmente envolvidos.

Na continuidade Michelli (2017) acrescenta que aproveitar a opinião do cliente é difícil. A maioria das empresas não pede informações suficientes de seus clientes ou pedem em intervalos de tempo mal estruturados. Algumas empresas pedem com tanta frequência que irritam seus clientes com constantes pesquisas detalhadas. $\mathrm{E}$ em ambos os casos, algumas empresas simplesmente não sabem como as respostas de seus clientes podem ser utilizadasem benefício dos próprios clientes que forneceram a informação. Para evitar estes e outros tipos de problemas, a Mercedes-Benz mapeou a "jornada do seu cliente', ou seja, mapeoucada ponto de contato, em tempo real, com a marca a fim de ser examinado e aprimorado. (Ibidem, 2017)

\section{Procedimentos Metodológicos}

Pretende-se com esse estudo analisar e identificar como as práticas da Experiência do Cliente juntamente com a Cultura da inovação podem trazer resultados às empresas.

Segundo Gil (2008) a pesquisa é o procedimento racional e sistemático que tem por objetivo proporcionar respostas aos problemas propostos pelo pesquisador. Sendo assim, a pesquisa é requerida quando não há informações suficientes ou quando esta informação se encontra em desordem, por isso este procedimento visa atender adequadamente este aspecto do problema pesquisa elencado.

A pesquisa também deve ser desenvolvida mediante a utilização dos conhecimentos disponíveis e cuidadosa aplicação da metodologia de pesquisa, técnicas e procedimentos científicos. Esta se desenvolve com inúmeras fases, isso quer dizer, desde a formulação do problema até a apresentação dos resultados. (GIL, 2008).

Diante do exposto, define-se esta pesquisa como exploratória de caráter qualitativo, uma vez que visa identificar e esclarecer a influência direta permitindo assim maior aproximação com o cotidiano e as experiências vividas pelos próprios sujeitos (Gil, 2011).

Na metodologia foi utilizado o estudo de caso e a aplicação de questionários construído com aparato teórico afim de coletar e analisar os dados obtidos através das boas práticas aplicadas em grandes empresas, sobre Cultura da Inovação, Customer Success e Experiência do Cliente.

Para Yin (2010) e, também, Pereira et al. (2018), o estudo de caso é uma investigação empírica de um fenômeno contemporâneo dentro de um contexto da vida real, sendo que os limites entre o fenômeno e o contexto não estão claramente definidos. Ainda segundo o mesmo autor, enfatiza ser a estratégia mais escolhida quando é preciso responder a questões do tipo "como" e "por quê" e quando o pesquisador possui pouco controle sobre os eventos pesquisados.

Para tanto, foram pesquisadas 24 pequenas de diversos segmentos de micro e pequeno porte, localizadas na região norte da cidade São Paulo, selecionadas pelo Sebrae.

Os dados referentes à pesquisa, foram divididos em 3 (três) perguntas principais e suas respectivas respostas enviadas pelas empresas que participaram do Projeto ALI SEBRAE-SP da zona norte de São Paulo.

Neste contexto, a primeira pergunta está relacionada com asdificuldades que as empresas encontraram ao longo da aplicação da metodologia do projeto, sendo analisada todas diretamente em um único gráfico (Gráfico 1); a segunda 
pergunta trata da vertente "Experiencia do Cliente", do Radar de Inovação, com 10 questões (Tabela 1). E a terceira pergunta trata da vertente "Cultura da Inovação" com 5 questões (Tabela 4.2).

Nesta pesquisa, buscou-se avaliar o grau de importância para as vertentes, sendo adotadas as seguintes convenções para resposta: 1=Pouco relacionado com minha empresa;até 5=Muito relacionado com minha empresa.

Os questionários completos, enviados aos entrevistados, sua tabulação e análise dos dados são apresentados no capítulo Análise e Discussão do Dados.

\section{Análise dos Dados}

Nesse capítulo será apresentado os dados referentes à pesquisa, divididos em 3 (três) perguntas principais e suas respectivas respostas enviadas pelas empresas que participaram do Projeto ALI SEBRAE-SP da zona norte de São Paulo.

\subsection{Pergunta: Qual foi sua maior dificuldade durante o Projeto ALI?}

Gráfico 1 - Qual foi sua maior dificuldade durante o Projeto ALI?

\section{Dificuldades durante o projeto}

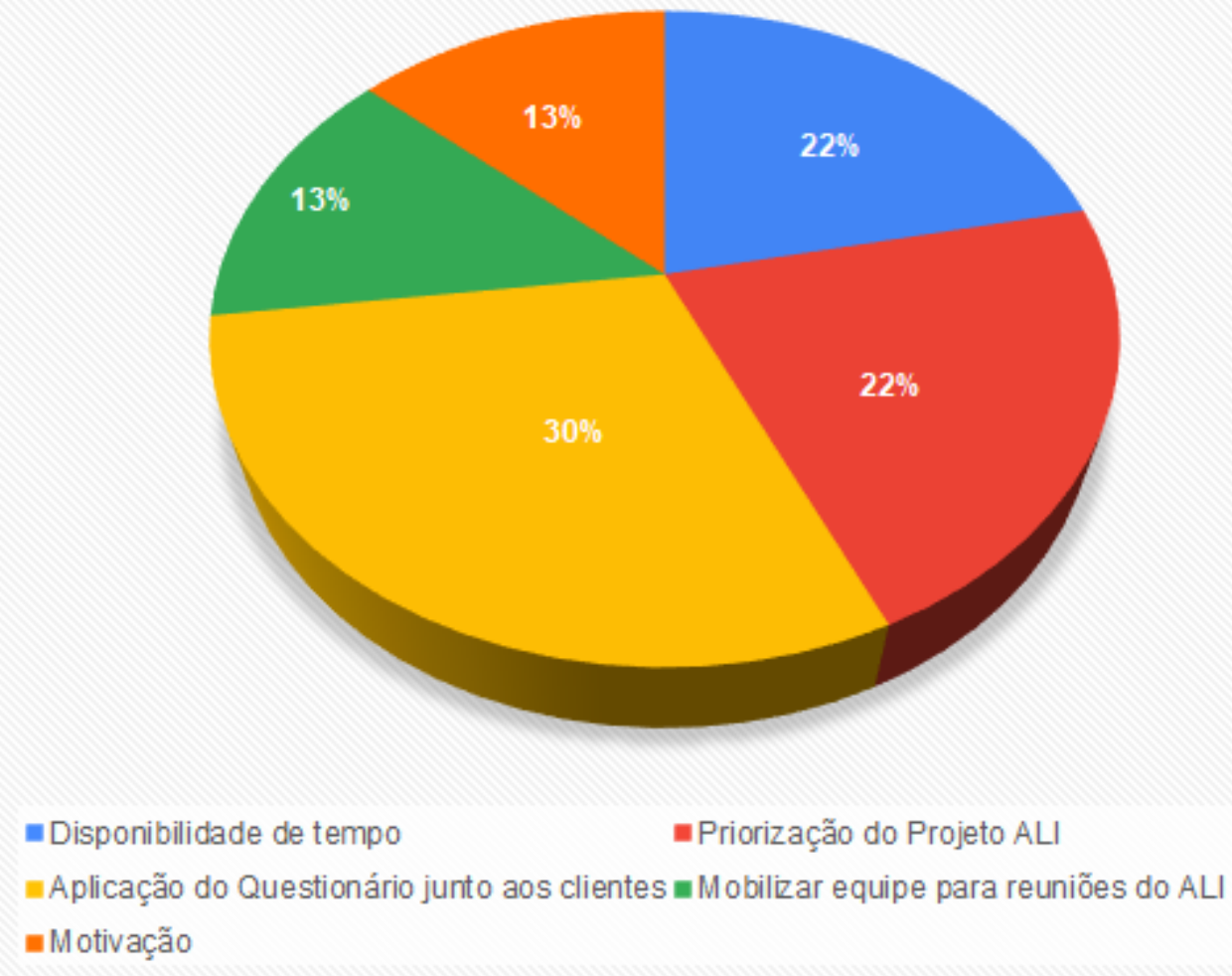

Fonte: Autores (2019)

$\mathrm{Na}$ análise dos dados coletados das empresas entrevistadas, conforme demonstrado no Gráfico 1 , das cinco maiores dificuldades levantadas durante a trajetória no projeto, verificou-se que o item “Aplicação do Questionário junto aos clientes" foi o quesito com maior grau de dificuldade entre os entrevistados (30\%), seguido pela "priorização dedicada ao projeto" (22\%) assim como a disponibilidade de tempo (22\%) as quais, estas últimas duas, somam um total de $44 \%$. 
Christensen, Hal, Dillon e Duncan (2010) argumentam que para observar o progresso que seu cliente está tentando fazer em determinado momento da vida dele. Compreender esse progresso é compreender o que seus clientes mais se importam, ou seja, entender o mecanismo causal de seus comportamentos.

\subsection{Pergunta: Na sua rotina com experiência do cliente, sua empresa...}

As respostas das questões referentes a pergunta "Na sua rotina com EXPERIÊNCIA DO CLEINTE, sua empresa...", estão tabuladas em quantidade de respondentes e o respectivo percentual sobre o total (Tabela 1).

Tabela 1 - Dados da pesquisa enviadas pelas empresas: "Na sua rotina com EXPERIÊNCIA DO CLEINTE, sua empresa...”

\begin{tabular}{|c|c|c|c|c|c|c|}
\hline Questão & $\begin{array}{l}\text { Na sua rotina com EXPERIÊNCIA DO } \\
\text { CLIENTE, sua empresa... }\end{array}$ & $\begin{array}{l}1=\text { Pouco } \\
\text { relacionado } \\
\text { com minha } \\
\text { empresa }\end{array}$ & 2 & 3 & 4 & $\begin{array}{l}5=\text { Muito } \\
\text { relacionado } \\
\text { com minha } \\
\text { empresa }\end{array}$ \\
\hline 1 & $\begin{array}{l}\text { Monitora seu cliente para saber o que ele } \\
\text { precisa. }\end{array}$ & $\begin{array}{c}(1) \\
4,17 \%\end{array}$ & $\begin{array}{c}(2) \\
8,33 \%\end{array}$ & $\begin{array}{c}(5) \\
16,67 \%\end{array}$ & $\begin{array}{l}(6) \\
25 \%\end{array}$ & $\begin{array}{c}(10) \\
41,67 \%\end{array}$ \\
\hline 2 & $\begin{array}{l}\text { Supera as expectativas de seu cliente durante o } \\
\text { atendimento, surpreendendo-o positivamente }\end{array}$ & $\begin{array}{l}(0) \\
0 \%\end{array}$ & $\begin{array}{l}(2) \\
8,33 \%\end{array}$ & $\begin{array}{c}(6) \\
25 \%\end{array}$ & $\begin{array}{c}(10) \\
41,67 \%\end{array}$ & $\begin{array}{l}(6) \\
25 \%\end{array}$ \\
\hline 3 & $\begin{array}{l}\text { Ignora a necessidade do cliente empurrado } \\
\text { para outros produtos/serviços dos quais ele } \\
\text { não se interessa. }\end{array}$ & $\begin{array}{c}(20) \\
83,33 \%\end{array}$ & $\begin{array}{c}(4) \\
16,67 \%\end{array}$ & $\begin{array}{l}(0) \\
0 \%\end{array}$ & $\begin{array}{l}(0) \\
0 \%\end{array}$ & $\begin{array}{l}(0) \\
0 \%\end{array}$ \\
\hline 4 & Realiza um atendimento personalizado & $\begin{array}{l}(0) \\
0 \%\end{array}$ & $\begin{array}{c}(1) \\
4,17 \%\end{array}$ & $\begin{array}{c}(2) \\
8,33 \%\end{array}$ & $\begin{array}{c}(7) \\
29,17 \%\end{array}$ & $\begin{array}{c}(14) \\
58,33 \%\end{array}$ \\
\hline 5 & $\begin{array}{l}\text { Não entende o tempo do cliente (quando } \\
\text { você aborda o clienteantes da hora ou tenta } \\
\text { estabelecer um contato forçado). }\end{array}$ & $\begin{array}{c}(16) \\
66,67 \%\end{array}$ & $\begin{array}{c}(2) \\
8,33 \% \\
\end{array}$ & $\begin{array}{c}(5) \\
20,83 \% \\
\end{array}$ & $\begin{array}{l}(0) \\
0 \%\end{array}$ & $\begin{array}{l}(1) \\
4,17 \%\end{array}$ \\
\hline 6 & $\begin{array}{l}\text { Prepara/treina seus funcionários para que } \\
\text { eles saibam como melhor conduzir o } \\
\text { atendimento afim de não perder a venda. }\end{array}$ & $\begin{array}{c}(1) \\
4,17 \%\end{array}$ & $\begin{array}{c}(6) \\
25 \%\end{array}$ & $\begin{array}{c}(5) \\
20,83 \%\end{array}$ & $\begin{array}{c}(5) \\
20,83 \%\end{array}$ & $\begin{array}{c}(7) \\
29,17 \%\end{array}$ \\
\hline 7 & $\begin{array}{l}\text { Após a venda, você ignora o cliente (não } \\
\text { determina estratégias de pós-venda que } \\
\text { que visam retê-lo e fidelizá-lo). }\end{array}$ & $\begin{array}{l}(12) \\
50 \%\end{array}$ & $\begin{array}{c}(5) \\
20,83 \%\end{array}$ & $\begin{array}{c}(4) \\
16,67 \%\end{array}$ & $\begin{array}{c}(3) \\
12,50 \%\end{array}$ & $\begin{array}{l}(0) \\
0 \%\end{array}$ \\
\hline 8 & $\begin{array}{l}\text { Possui processos com muitas etapas e } \\
\text { equipes envolvidas, fazendo com que o } \\
\text { atendimento seja lento e burocrático. }\end{array}$ & $\begin{array}{c}(11) \\
45,83 \%\end{array}$ & $\begin{array}{c}(4) \\
16,67 \%\end{array}$ & $\begin{array}{c}(4) \\
16,67 \%\end{array}$ & $\begin{array}{c}(4) \\
16,67 \%\end{array}$ & $\begin{array}{l}(1) \\
4,17 \%\end{array}$ \\
\hline 9 & $\begin{array}{l}\text { Não estabelece métricas para medir a satisfação } \\
\text { de seu cliente(saber o que ele deseja) }\end{array}$ & $\begin{array}{c}(6) \\
25 \%\end{array}$ & $\begin{array}{c}(5) \\
20,83 \%\end{array}$ & $\begin{array}{c}(6) \\
25 \%\end{array}$ & $\begin{array}{c}(4) \\
16,67 \%\end{array}$ & $\begin{array}{c}(3) \\
12,50 \%\end{array}$ \\
\hline 10 & $\begin{array}{l}\text { Falta de organização e controle gerando } \\
\text { atendimentos repetidos,custos adicionais, além } \\
\text { de aumentar a insatisfação dos } \\
\text { clientes. }\end{array}$ & $\begin{array}{c}(15) \\
62,50 \%\end{array}$ & $\begin{array}{c}(3) \\
12,50 \%\end{array}$ & $\begin{array}{c}(2) \\
8,33 \%\end{array}$ & $\begin{array}{c}(3) \\
12,50 \%\end{array}$ & $\begin{array}{c}(1) \\
4,17 \%\end{array}$ \\
\hline
\end{tabular}

Fonte: Autores (2019).

Ao verificar os dados da Tabela 1 referentes a Questão 1: "Monitora seu cliente para saber o que ele precisa", notase que 10 empresas $(41,67 \%)$ das 24 pesquisadas indicaram a que tal atividade é muito relacionado com as maiorias das 
empresas pesquisadas. Isso revela que existe uma preocupação em colocar o cliente como objetivo principal antes de criar soluções.

Quando se observa os dados da Tabela 1 referentes a Questão 2: "Monitora seu cliente para saber o que ele precisa", 10 respostas $(41,67 \%)$ revelam que essa atividade tem um grau de relação considerável com as práticas das empresas pesquisadas. Se, juntados às respostas do indicador de número 5 (muito relacionado com a minha empresa) somam 66, 67\% . Estes indicadores mostram que uma parcela significativa destas empresas se preocupa com tal atividade e a faz o monitoramento de forma constante, demonstrando a importância para as empresas fomentar tal rotina.

Já os dados referentes da Tabela 1 para a Questão 3: "Ignora a necessidade do cliente empurrando para outros produtos/serviços dos quais ele não se interessa", obteve 20 respostas $(83,33 \%)$. Isso mostra a importância da prática de tal atividade no atendimento aos interesses do cliente e não, necessariamente, aos interesses apenas de vender produtos da empresa ao mesmo.

Ao ponderar os dados referentes da Tabela 1 na Questão 4: "Realiza um atendimento personalizado", notou-se que 14 respostas $(58,33 \%)$ demonstram é de essencial preocupação entre as empresas pesquisadas com um tem um grau de muita relação com as práticas das empresas pesquisadas. Pode-se indicar que essas empresas tentam ter altos níveis de atendimento na busca da personalização, em suas atividades, voltadas ao cliente.

Os dados referentes da Tabela 1 para a Questão 5: "Não entende o tempo do cliente (quando você aborda o cliente antes da hora ou tenta estabelecer um contato forçado).", obteve 16 respostas (66,67\%) das empresas pesquisadas. Indicando que tal atividade tem pouca relação com essas empresas e essa prática pode não ser bem-vista pela maioria dos empreendedores uma vez que, o uso corrente dessa prática não viabiliza fechamentos de negócios e atendimento das reais necessidades dos clientes.

Ao analisar os dados referentes da Tabela 1 na Questão 6: "Prepara/treina seus funcionários para que eles saibam como melhor conduzir o atendimento a fim de não perder a venda.", viu-se que 07 dos respondentes $(29,17 \%)$, maioria nessa questão, indicaram que tal atividade é muito relacionado com as maiorias das empresas pesquisadas. Isto nos revela a preocupação dessas empresas em treinar/preparar seus funcionários, bem como ressalta a importância da condução de atender melhor seus clientes como estratégia para não perder vendas.

Quando se observar os dados referentes da Tabela 1 para a Questão 7: "Após a venda, você ignora o cliente (não determina estratégias de pós-venda que visam retê-lo e fidelizá-lo).", 12 das 24 respostas (41,67\%) demonstram que essa atividade tem pouca relação com a maioria das empresas pesquisadas. Tais indicadores podem mostrar que existe uma preocupação com o pós venda, ou seja, a checagem dos principais pontos de contato que o cliente pode ter após a compra.

Ao verificar os dados referentes da Tabela 1 na Questão 8: "Possui processos com muitas etapas e equipes envolvidas, fazendo com que o atendimento seja lento e burocrático.", nota-se que 11 respondentes $(45,83 \%)$ indicaram que tal atividade é pouco relacionado com a maioria das empresas pesquisadas, mostrando a preocupação dessas empresas em atender prontamente seu cliente, com rapidez e eficiência.

Referente os dados da Tabela 1 para a Questão 9: "Não estabelece métricas para medir a satisfação de seu cliente (saber o que ele deseja).", obteve 6 respostas (25\%) das empresas pesquisadas para o indicador 2. Se, juntados às respostas do indicador de número 1 (pouco relacionado com a minha empresa) somam $45,837 \%$. Isso nos alerta para a falta de visão da maioria dos empreendedores os quais poderiam utilizaras métricas para medir a satisfação de seu cliente e, assim, gerar novas vendas e novos negócios. E, também, mostra a importância da prática de tal atividade no atendimento aos interesses do cliente e não, necessariamente, aos interesses apenas de vender produtos da empresa ao mesmo.

Os dados referentes da Tabela 1 na Questão 10: "Falta de organização e controle gerando atendimentos repetidos, custos adicionais, além de aumentar a insatisfação dos clientes.", obteve 15 respostas $(62,50 \%)$ das empresas pesquisadas. 
Assim como a questão 5, comentada anteriormente, tal atividade tem pouca relação com essas empresas e essa prática pode não ser bem-vista pela maioria dos empreendedores uma vez que, o uso corrente dessa prática não viabiliza fechamentos de negócios e atendimento das reais necessidades dos clientes.

\subsection{Pergunta: Na sua rotina com cultura da inovação, na sua empresa....}

As respostas das questões referentes a pergunta "Na sua rotina com CULTURA DA INOVAÇÃO, na sua empresa...”, estão tabuladas em quantidade de respondentes e o respectivo percentual sobre o total (Tabela 2).

Tabela 2: Dados da pesquisa enviadas pelas empresas: "Na sua rotina com CULTURA DA INOVAÇÃO, na sua empresa..."

\begin{tabular}{|c|c|c|c|c|c|c|}
\hline Questão & $\begin{array}{l}\text { Na sua rotina com CULTURADA } \\
\text { INOVAÇÃO, na sua empresa... }\end{array}$ & $\begin{array}{l}1=\text { Pouco } \\
\text { relacionado } \\
\text { com minha } \\
\text { empresa }\end{array}$ & 2 & 3 & 4 & $\begin{array}{l}5=\text { Muito } \\
\text { relacionado } \\
\text { com minha } \\
\text { empresa }\end{array}$ \\
\hline 1 & $\begin{array}{l}\text { Tem dificuldades de tirar as ideias do } \\
\text { papel. }\end{array}$ & $\begin{array}{c}(6) \\
25 \%\end{array}$ & $\begin{array}{c}(7) \\
29,17 \% \\
\end{array}$ & $\begin{array}{c}(2) \\
8,33 \% \\
\end{array}$ & $\begin{array}{c}(6) \\
25 \%\end{array}$ & $\begin{array}{c}(3) \\
12,50 \%\end{array}$ \\
\hline 2 & Tem medo de assumir riscos. & $\begin{array}{l}(11) \\
50 \%\end{array}$ & $\begin{array}{c}(5) \\
20,83 \%\end{array}$ & $\begin{array}{c}(5) \\
20,83 \%\end{array}$ & $\begin{array}{c}(2) \\
8,33 \%\end{array}$ & $\begin{array}{l}(0) \\
0 \%\end{array}$ \\
\hline 3 & $\begin{array}{l}\text { Possui uma cultura conectada em que a } \\
\text { ideia de compartilhamento seja facilitada e } \\
\text { onde todas as pessoas que contribuíram para } \\
\text { algo sejam reconhecidas e recompensadas. }\end{array}$ & $\begin{array}{c}(1) \\
4,17 \%\end{array}$ & $\begin{array}{c}(4) \\
16,67 \%\end{array}$ & $\begin{array}{c}(6) \\
25 \%\end{array}$ & $\begin{array}{c}(2) \\
8,33 \%\end{array}$ & $\begin{array}{c}(8) \\
33,33 \%\end{array}$ \\
\hline 4 & $\begin{array}{l}\text { Desenvolve uma série de métricas para } \\
\text { decidir que produtos ou serviços devem ser } \\
\text { criados ou abandonados. }\end{array}$ & $\begin{array}{c}(6) \\
25 \%\end{array}$ & $\begin{array}{c}(5) \\
20,83 \%\end{array}$ & $\begin{array}{c}(5) \\
20,83 \%\end{array}$ & $\begin{array}{c}(3) \\
12,50 \%\end{array}$ & $\begin{array}{c}(5) \\
20,83 \%\end{array}$ \\
\hline 5 & $\begin{array}{l}\text { Existe trabalho em equipe e os funcionários } \\
\text { participam de treinamentos }\end{array}$ & $\begin{array}{c}(2) \\
8,33 \%\end{array}$ & $\begin{array}{c}(4) \\
16,67 \%\end{array}$ & $\begin{array}{c}(4) \\
16,67 \%\end{array}$ & $\begin{array}{c}(5) \\
20,83 \%\end{array}$ & $\begin{array}{c}(9) \\
37,50 \%\end{array}$ \\
\hline
\end{tabular}

Fonte: Autores (2019).

Ao verificar os dados referentes da Tabela 2 na Questão 1: "Tem dificuldades de tirar as ideias do papel.", nota-se que 7 empresas $(29,17 \%)$ das 24 pesquisadas responderam o indicador 3, o que dá a entender que essas empresas têm uma média dificuldade de tirar as ideias do papel. Por outro lado, ao verificar-se os indicadores extremos 1 e 2 (com 33,33\%) e os extremos 4 e $5(37,50 \%)$, pode-se pensar que uma parcela significativa $(37,50 \%)$ realmente que sente tais dificuldades em seu dia a dia.

Quando se observa os dados referente da Tabela 2 para a Questão 2: "Tem medo de assumir riscos.", 12 respostas (50\%), metade dos entrevistados, revelam que essa atividade tem pouca relação com as rotinas das empresas pesquisadas. Chama a atenção que nenhuma empresa (0\%) respondeu o indicador número 5 (muito relacionado com a minha empresa) o que nos remete a condição na qual para ser empreendedor correr riscos é uma de suas características principais.

Já os dados referentes da Tabela 2 na Questão 3: "Possui uma cultura conectada em que a ideia de compartilhamento seja facilitada e onde todas as pessoas que contribuíram para algo sejam reconhecidas e recompensadas.", obteve 8 respostas (83,33\%) no indicador 5 (muito relacionado com a minha empresa). Isso pode demonstrar a importância dessa rotina para a empresa no tocante ao alcance de seus objetivos estratégicos de forma a motivar seus colaboradores.

Referente aos dados da Tabela 2, no que diz respeito a Questão 4: "Desenvolve uma série de métricas para decidir que produtos ou serviços devem ser criados ou abandonados.", obteve 6 respostas (25\%) para o indicador 1 (Pouco relacionado com minha empresa) das empresas pesquisadas. Dá-nos a impressão de que uma parcela significativa não se 
importa com tal rotina, o que é grave uma vez que empresas que pensam contrário ao exposto não caracterizam como empresas inovadoras. E se, analisar-se os indicadores extremos 1 e 2 (com 45,83\%) e os extremos 4 e 5 (32,50\%), reforça ainda mais tal análise aqui exposta.

Os dados referentes da Tabela 2 para a Questão 5: "Existe trabalho em equipe e os funcionários participam de treinamentos.", obteve 9 respostas $(37,50 \%)$ para o indicador 5 (muito relacionado com a minha empresa), o que nos leva a pensar de que uma parcela significativa das empresas faz uso dessa rotina de forma a causar sinergia e condições de desenvolvimento aos seus funcionários.

\subsection{Impacto das principais ações implementadas}

Pôde se ter a oportunidade de aplicar questionários às empresas participantes do Projeto Agente Local de Inovação (ALI), e com isso analisar e identificar, perante as respostas destes questionários, o pensamento sobre as práticas da Experiência do Cliente juntamente com a Cultura da Inovação e, com isso, trazer resultados às empresas pesquisadas.

Metha, Steinman e Murphy (2019) ressalta que todos os negócios sofrerão disrupção em favor de seus clientes, ou seja, todos os negócios terão de concentrar suas energias e investimentos para cuidar de seus clientes. E o sucesso do cliente tem a ver, com lealdade e a necessidade de preservá-los. Tentar superar as taxas de evasão com a conquista de novos clientes é extremamente oneroso. Portanto, se uma empresa depende da lealdade dos clientes, é fundamental compreender o que significa essa palavra.

Trías de Bes e Kotler (2011) questiona sobre a diferença entre uma ideia e uma inovação. E, traz claramente a seguinte resposta: a inovação oferece maior valor para o cliente.

O Instituto Disney (2011) ao investigar a ligação entre a cultura da excelência na experiência do hóspede e o desempenho geral dos negócios da empresa, notou que, em essência, os hóspedes da Disney que ficavam encantados com sua experiência produziamlucro significativo, o que, por sua vez, encantava os acionistas. Para a Disney as emoções são os sentimentos que os clientes vivenciam no contato com sua organização, com uma ampla variedade de emoções durante a visita, pois eles querem mais do que simples férias; eles também querem memórias duradouras de uma experiência familiar repleta de diversão.

As vertentes cultura da inovação e experiência do cliente devem estar profundamente enraizadas no cerne das empresas e devem ser sustentadas ao longo de suas operações diárias de negócios, pois são temas vivos, não apenas uma frase em uma placa e devem satisfazer três necessidades críticas: a clareza do propósito de uma empresa, transmitir internamente a seus colaboradores uma mensagem clara e criar uma imagem para a organização.

As empresas pesquisadas percebem que é impossível inovar se não prestarem atenção no consumidor final. E a inovação real criada, seja ela, produto, serviço, forma de comercialização, processos, estrutura de parceria, mais cedo ou mais tarde deve ser aceitapelo cliente final, que tomará a iniciativa de validar ou não a inovação proposta. Essamudança de postura de consumo, envolve um esforço que o consumidor só fará se obtiver um benefício claro e superior dele.

O estudo etnográfico que o Projeto ALI propõe com a metodologia do Job to be done traz a mudança de postura das empresas em observar os comportamentos do consumidor, os questionamentos pessoais com bases nas quatro forças emocionais (incômodos, motivações, hábitos e ansiedades) que inspiram as empresas a obter ideias que os próprios consumidores nunca teriam sido capazes de verbalizar. E essa compreensão do comportamento corrente dos consumidores tem muito mais chances de serem bem-sucedidas.

A aplicação da metodologia foi percebida pelas empresas pesquisadas no sentido de melhorar a vida dos clientes, observar seus progressos e imaginar modos de enriquecer suas vidas. Práticas têm sido planejadas à médio prazo, no sentido de implantação de um cuidado maior antes, durante e após o consumo de produtos e serviços. 


\subsection{Aprendizado do ALI enquanto pesquisador}

Enquanto pesquisadora, o universo da diversidade de segmentos visitados trouxe uma grande visão sistêmica das diversas fontes de ideias de inovação quando é lançado um olhar para a cadeia de trabalho em si, como funcionários, parceiros, clientes, consultores, concorrentes, eventos diversos e de como a colaboração deve fazer parte deste novo universo do consumo.

Percebe-se a necessidade da reinvenção a todo tempo, deixar de lado a zona de conforto a que normalmente aprendemos a desejar. A importância de influenciar pessoas por meio da autenticidade se torna um cotidiano, a empatia, um dever como qualquer consultor oupessoa que se preste a dar mentoria, repassar uma metodologia, ajudar a criar oportunidades e contribuir positivamente com a economia, ao futuro do trabalho. A criatividade, persistência, resiliência e liberdade são percepções as quais aumentam com o passar destes meses.

\section{Considerações Finais}

Há muitas empresas que necessitam passar por uma profunda mudança no aprimoramento de sua gestão e principalmente nos comportamentos empreendedores e por conta desse atraso gerencial e comportamental não conseguiram compreender e aplicar as ferramentas da metodologia.

Por outro lado, as empresas que já possuem em seu cerne as questões da inovação, que acompanham seus mercados, interagem entre si com seus pares e até seus concorrentes, puderam dar um passo significativo e marcante em sua gestão, mudando inclusive sua modelagem do negócio.

No primeiro preenchimento do Radar de Inovação que é realizado na oficina de arregimentação do Programa, algumas das vertentes devem ser explicadas e detalhadas aos participantes, pois deixam muitas margens de dúvida na interpretação de seu conceito, levando o empresário a escolher um nível de resposta que não representa a realidade da sua empresa. Isso acaba interferindo no andamento do Projeto quando a empresa já está participando juntamente com o Agente local de inovação.

\subsection{Trabalhos futuros}

Como sugestões para trabalhos futuros entende-se que as empresas possam estudar um sistema de recompensas para seus colaboradores para estimular a cultura da inovação - financeiro, participação nas vendas, reconhecimento público, tempo para pensar, entre outros).

Outro ponto que a ser discutido é de um estudo para que as empresas criem níveis de categorias de interação com o cliente, com foco no relacionamento coletivo ao invés do individual, com isso poderá haver possibilidades de proporcionar uma melhor conexão destes clientes a estas empresas.

\section{Agradecimentos}

Ao Sebrae por ter possibilitado a experiência de atuar em campo, como Agente Local de Inovação e realizar a pesquisa junto as micro e pequenas empresas, propiciando a associação de conhecimentos técnicos e acadêmicos, contribuindo assim com meu crescimento enquanto profissional e pesquisadora. Agradeço à gestora do escritório regional Capital Norte, Camila Patrício, pela confiança, amizade e apoio durante o processo de atuaçãoem campo.

Ao CNPq (Conselho Nacional de Desenvolvimento Científico e Tecnológico), pelabolsa de estudos e auxílio financeiro que possibilitou a dedicação integral ao Programa ALI. 
Aos meus pais e irmão, pela ajuda e compreensão nos momentos de ausência.

As pessoas e empresas pesquisadas, pela colaboração e informações necessárias para viabilizar este trabalho.

Ao Professor Doutor Osmildo Sobral dos Santos pela orientação, confiança, tempo dedicado ao meu auxílio e sugestões construtivas que contribuíram de forma expressiva para odesenvolvimento deste artigo.

\section{Referências}

Chiavenato, I. (2005) Gerenciando com as pessoas: transformando o executivo em um excelente gestor de pessoas: um guia para o executivo aprender a lidar com sua equipede trabalho. Elsevier.

Christensen C., Hall T., Dillon K., \& Duncan D. (2010) Muito Além da Sorte: Processos Inovadores para Entender o que os Clientes. Editora Bookman.

Davis, K., \& Newstrom J.W. (1996) Comportamento Humano no Trabalho: uma abordagemorganizacional. Cengage Learning Edições.

Disney Institute. (2011) O jeito Disney de encantar os clientes: do atendimentoexcepcional ao nunca parar de crescer e acreditar. Saraiva.

Dyer, W. G, Dyer Jr, W. Gibb, \& Dyer, J. H. (2011) Equipes que fazem a diferença (team building): estratégias comprovadas para desenvolver equipes de alta performance. São Paulo: Saraiva.

Fonseca, L. S., Salles, D. M. R., Santos, J. A. N., \& Freitas, A. P. A. (2021) Análise da escala de valores organizacionais em empresas com estrutura de gestão familiar. Research, Society and Development, 10(6), e15110615449, 1-15.

Gil, A. C. (2008) Como elaborar projetos de pesquisa. (4a ed.), Atlas.

Gil, A. C. (2011). Gestão de Pessoas: Enfoque nos Papéis Profissionais. Atlas.

Kotler, P., Kartajaya, H., \& Setiawan, I. (2012) Marketing 3.0: as forças que estão definindo o novo marketing centrado no ser humano. Rio de Janeiro: Elsevier.

Metha, N., Steinman, D., \& Murphy L. (2019) Customer Success como as empresas inovadoras descobriram que a melhor forma de aumentar a receita é garantir o sucessodos clientes. Autêntica Business.

Michelli, J. A. (2017) Guiados pelo Encantamento: o método Mercedes-Benz para entregar amelhor experiência do cliente. DVS Editora.

Mintzberg, H,, Ahlstrand, B., \& Lampel, J. (2010) Safári de estratégia: um roteiro pela selva do planejamento estratégico. Bookman.

Morais, M. O., Brejão A. S., Santos, O. S., \& Costa Neto, P. L. O. (2019) Organização para inovação nas empresas: proposta de modelo integrando estratégia e estrutura organizacional. Brazilian Journal of Development, 5(10), 18632-18650.

Morais, M. O., Costa Neto, P. L. O., Santos, O. S. et al. (2020) O conhecimento aliado a inovação, elementos para a melhoria de processos produtivos: estudo de caso em uma fundição de alumínio sob pressão. Research, Society and Development, 9(9), e172997419, 1-15.

Pereira A. S. et al. (2018). Metodologia da pesquisa científica. UFSM. https://repositorio.ufsm.br/bitstream/handle/1/15824/Lic_Computacao_MetodologiaPesquisa-Cientifica.pdf?sequence $=1$.

Pine II, B. J., \& Gilmore, J.H. (1999) O espetáculo dos negócios. Campus.

Santos, O. S. (2006) Administração de Materiais como Elemento para a Qualidade e Produtividade. Dissertação de Mestrado, Programa de Mestrado em Engenharia de Produção, São Paulo: Universidade Paulista (UNIP),

Schumpeter, J. (1982). Teoria do Desenvolvimento Econômico, trad. Maria Sílvia Possas. Editora Abril.

Terra, J. C. C. et al. (2007) Inovação: quebrando paradigmas para vencer. São Paulo: Saraiva.

Terra, J. C. C. (2012) 10 Dimensões da gestão da Inovação: Uma abordagem para atransformação organizacional. Elsevier.

Trías de Bes, F., \& Kotler, P. (2011) A Bíblia da Inovação. Leya.

Yin, R. K. (2010). Estudo de caso: planejamento e métodos. (2a ed.) Bookman.

Zeithaml, V. A. et.al. (1990) Delivering quality service. Free Press. 